\title{
Nonlinear Behavior of Beams Having Initially Small Imperfection Subjected to Sinusoidal Load
}

\author{
Ayfer TEKIN ATACAN*, Receb Faruk YÜKSELER \\ Yildiz Technical University, Department of Civil Engineering, Istanbul \\ (ORCID: 0000-0001-8161-1345) (ORCID: 0000-0002-2733-580X)
}

\begin{abstract}
In the present study, the buckling and postbuckling behaviors of beams having initially small sinusoidal imperfection with pinned ends subjected to sinusoidal loading are examined by using Euler-Bernoulli beam theory. The governing differential equations of the geometrically nonlinear problem consisting of the equilibrium equations, kinematical equations and the constitutive equations are converted into algebraic equations via the finite differences and solved numerically by using the Newton-Raphson method. The values of buckling loads and buckling deflections are determined by drawing load-deflection curves. The effect of the initial imperfection on the buckling values is investigated. It is seen that as the value of the small initial imperfection is increased, the buckling force is increased and buckling deflection is decreased. Unlike previous studies on the subject, the diagrams of the deformed shapes of the beam having initially small imperfection as well as the diagrams of the internal forces at various stages of the deformation including the prebuckling, buckling and postbuckling states are presented for various values of the initial imperfection.
\end{abstract}

Keywords: Snap-through instability, initially imperfect beam, nonlinear equation, finite differences method, buckling.

\section{Sinüzoidal Yük Etkisindeki Küçük İlkel Kusurlu Kirişlerin Doğrusal Olmayan Davranışı}

\begin{abstract}
$\ddot{O} \mathbf{z}$
Bu çalışmada; sinüzoidal yüke maruz, uçları sabit mesnetli, başlangıçta küçük sinüzoidal kusura sahip kirişlerin burkulma ve burkulma sonrası davranışları Euler-Bernoulli kiriş teorisi kullanılarak incelenmiştir. Denge denklemleri, kinematik denklemler ve bünye denklemlerini içeren, geometrik olarak doğrusal olmayan problemin yönetici diferansiyel denklemleri, sonlu farklar yöntemi ile cebirsel denklemlere dönüştürülmüş ve NewtonRaphson yöntemi kullanılarak sayısal olarak çözülmüștür. Burkulma yükleri ve burkulma çökmelerinin değerleri, yük-çökme eğrileri çizilerek belirlenmiştir. İlkel kusurun burkulma değerleri üzerindeki etkisi incelenmiştir. Küçük ilkel kusurun değeri arttıkça, boyutsuz burkulma yükünün arttı̆̆ı ve boyutsuz burkulma yer değiştirmesinin azaldığı görülmüştür. Konuyla ilgili daha önceki çalışmalardan farklı olarak; başlangıçta sinüzoidal ilkel kusurlu kirişlerin, şekil değiştirmenin çeşitli aşamalarındaki elastik eğri diyagramlarının yanı sıra; burkulma öncesindeki, burkulma sırasındaki ve burkulma sonrasındaki durumlarına karşı gelen kesit tesirlerinin diyagramları ilkel kusurun çeşitli değerleri için sunulmuştur.
\end{abstract}

Anahtar kelimeler: Vurgu tipi stabilite, ilkel kusurlu kiriş, doğrusal olmayan denklem, sonlu farklar yöntemi, burkulma.

\section{Introduction}

The postbuckling behavior is an important phenomenon to investigate initially imperfect beams (or curved beams or arches) basing on their snap-through motion. Curved beams which have different

"Corresponding author: atekin@yildiz.edu.tr

Received: 17.07.2019, Accepted: 18.10.2019 
mechanical behavior than the straight ones can resist both axial compression and bending actions. They were frequently used in microelectromechanical system (MEMS) devices such as switches, sensors and actuators. Experimental and numerical results of the snap-through instability in MEMS based applications were presented in [1-5].

There were numerous studies investigating snap-through buckling for various beam geometries and loading conditions. For example, Bradford et al. [6] studied analytically in-plane elastic stability of both pin-ended and fixed circular arches subjected to a central concentrated load; Chen et al. [7] found exact static and dynamic buckling loads for a pinned sinusoidal arch under a point force at the midpoint; Moon et al. 2007 [8] examined pinned shallow parabolic arches under a vertically distributed load to evaluate the buckling load; Hu et al. [9] investigated buckling and postbuckling of parabolic arches under a uniform vertical load; Fung and Kaplan [10] analyzed the buckling problem of pinned shallow arches of various initial imperfections (parabolic, half-sine, circular, etc.), and spatial distributions of the lateral load. Simitses and Hodges [11] gave a model for snapping of shallow pinned arches resting on an elastic foundation.

There have been a few studies that show the diagrams of the deformed shapes and the internal forces of the curved beams regarding the prebuckling, buckling and postbuckling states. Luu and Lee [12] presented a study on the buckling and postbuckling behaviors of elliptical curved beams subjected to a central concentrated vertical load and illustrated the deformed shapes of the semi-elliptical curved beam at various stages during the loading. Ning Lui et al. [13] gave a brief study in order to see snapthrough behaviors of toggle frames subjected to various types of thermal and mechanical loads including localized heating. They showed the deformation process of toggles at various stages during the snapthrough process. Tsiatas and Babouskos [14] studied the linear and geometrically nonlinear problem of non-uniform shallow arches under a central concentrated force. They determined the value of the buckling load for the given parameters and presented the normal displacement, the axial force, the shear force and the bending moment diagrams corresponding to the loads which were equal, smaller and larger than the buckling load.

In this study, snap-through analyses of pinned beam having initially sinusoidal small imperfection under sinusoidal loading are considered. The governing differential equations of the geometrically nonlinear problem are converted into algebraic equations via the finite differences and solved numerically by using the Newton Raphson method. The load-deflection curves corresponding to various amplitudes of the imperfection are drawn and the buckling values are determined. The diagrams of the deformed shapes and the diagrams of the internal forces of the beam having initially sinusoidal small imperfection corresponding to the various stages of the loading including the prebuckling, buckling and postbuckling states are drawn.

\section{Formulation of the Problem}

Geometric initial imperfections are among the main factors affecting the stability of structural systems and in fact, no element is perfect. Many structural elements may get initial geometric imperfections during their manufacturing and/or transporting processes. Therefore, a small geometric imperfection is initially added to the beam in order to examine the effect of the probable initial imperfection on the buckling problem of the structural element. In this study, the initially small imperfection is idealized to be in a sinusoidal form. Figure 1 shows an elastic pin-ended beam having initially small imperfection subjected to a sinusoidal loading. The initial deflection (imperfection) of any point of the beam is denoted by,

$$
w_{0}(x)=\delta \sin \left(\frac{\pi x}{L}\right) \text {. }
$$

The height of the midpoint of the beam having initially small imperfection before the deformation is denoted by $\delta$. The horizontal distance between the two pinned supports is indicated by $L$. The expression of the sinusoidal distributed load is as follows:

$$
q(x)=q_{0} \sin \left(\frac{\pi x}{L}\right) \text {. }
$$

Here, $q_{0}$ indicates the magnitude of the distributed load at $x=L / 2$. 
$\mathrm{q}(\mathrm{x})$

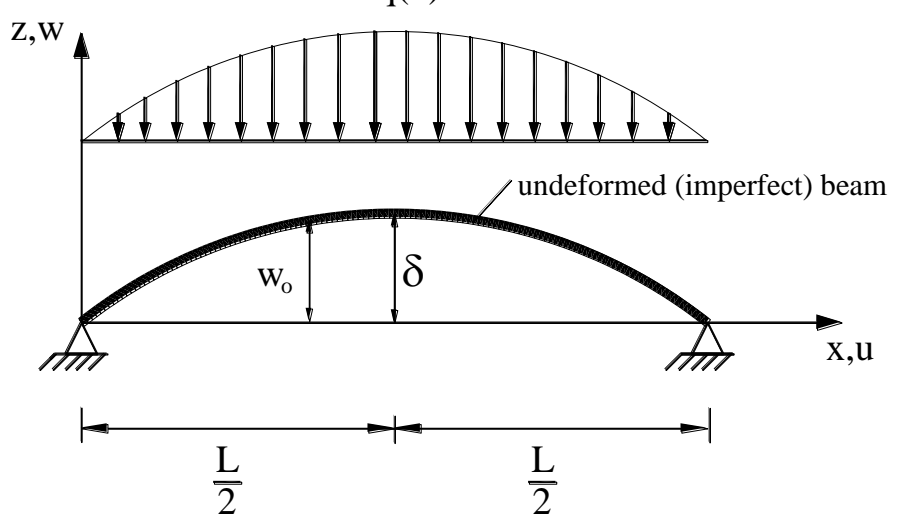

Figure 1. A half-sine pinned beam having initially sinusoidal small imperfection under half-sine loading acting along the entire span

The Euler-Bernoulli hypothesis is used in this study. According to this hypothesis, the kinematical equations are as follows:

$$
\varepsilon_{x x}=\varepsilon^{0}-z \bar{\kappa}, \varepsilon_{z z}=\gamma_{x z}=0
$$

where $\varepsilon_{x x}$ is the normal strain at any material point located at point $\mathrm{z}$ from the neutral surface, $\varepsilon_{z z}$ is the strain of the $\mathrm{z}$ direction, $\gamma_{x z}$ is the shear strain, $\varepsilon^{0}$ is the neutral axis strain, $\bar{\kappa}$ is the change in curvature which are defined as

$$
\varepsilon^{0}=u_{, x}+\frac{1}{2}\left(w_{, x}\right)^{2}-\frac{1}{2}\left(w_{o, x}\right)^{2}, \quad \bar{\kappa}=\bar{w}_{, x x} .
$$

Here; $u$ is the axial displacement, $w$ shows the final position of the deformed beam in the $\mathrm{z}$ direction, which is composed of two parts, namely, the initial deflection $w_{0}$ owing to the initial imperfection and the vertical deflection $\bar{w}$ due to the pure bending. The final rotation angle $\varphi(x)$ is the sum of the rotation $\varphi_{0}(x)$, due to the initial imperfection, and $\bar{\varphi}(x)$ caused by the pure bending. The relationship between deflection and rotation is

$$
\varphi=w_{, x} .
$$

The equations of equilibrium can be derived as

$$
\begin{aligned}
& -V_{, x}+q=0, \\
& -M_{, x}+V+N\left(\varphi_{0}+\bar{\varphi}\right)=0, \\
& N_{, x}=0
\end{aligned}
$$

where $M$ is the bending moment, $N$ is the normal force and $V$ is the effective shear force (composed of the summation of the shear force $Q$ known from the elementary theory, shown in Figure 2, and the projection of the normal force in the vertical direction, which can be verified through the variational calculus or though the free body diagram of a deformed element). It can be emphasized that the normal force $N$ can be assumed to be constant throughout the initially imperfect beam due to being shallow of the initially imperfect beam and it is equal to the horizontal support reaction $H$. 


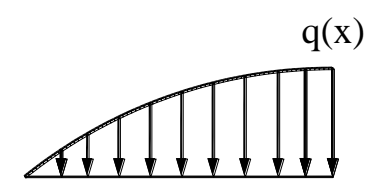

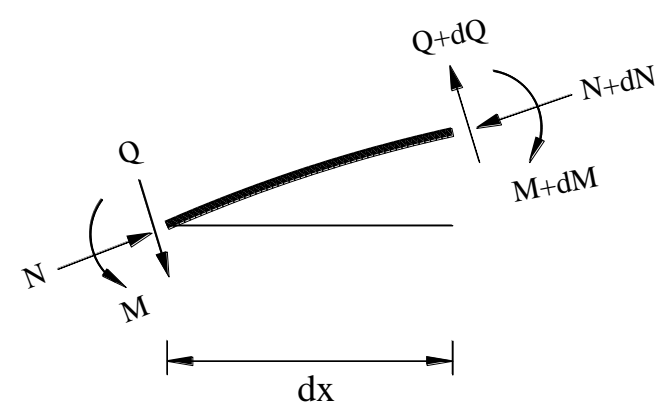

a)

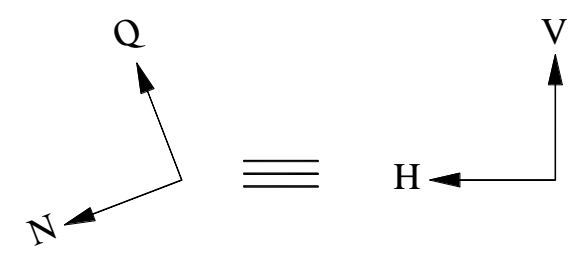

b)

Figure 2. a) Internal forces on a differential arc-element, b) equivalent forces

Assuming that the strains are very small, the constitutive relation is

$$
\sigma_{x x}=E \varepsilon_{x x}
$$

where $\sigma$ is the normal stress and $E$ is the modulus of elasticity.

The normal force and the bending moment can be expressed as

$$
\begin{aligned}
& N=\int_{A} \sigma d A, \\
& M=\int_{A} z \sigma d A,
\end{aligned}
$$

respectively. Using Eqs. (3)-(4), (8)-(10) and considering that horizontal deflections of pinned ended are zero, $u(0)=u(L)=0$, the following expression for the normal force can be obtained as

$$
N=\frac{E A}{2 L} \int_{0}^{L}\left(\varphi_{0}^{2}-\varphi^{2}\right) d x=H
$$

where $A$ is the cross-sectional area. Using Eqs. (3)-(4), (9), (11), the following constitutive equation for the bending moment can be obtained as

$$
M=-E I \bar{\varphi}_{, x}
$$

where $I$ is the moment of inertia. The boundary conditions for the concerning problem can be introduced as follows:

$$
\bar{w}(0)=\bar{w}(L)=0, M(0)=M(L)=0 .
$$

For convenience, nondimensional parameters with asterisks can be introduced as

$$
\begin{aligned}
& x^{*}=\frac{\pi x}{L}, r^{2}=\frac{I}{A}, \varphi^{*}=\left(\frac{L}{\pi r}\right) \varphi, w_{0}^{*}=\frac{w_{0}}{r}, \bar{w}^{*}=\frac{\bar{w}}{r}, \delta^{*}=\frac{\delta}{r}, \\
& q^{*}=\frac{q}{E I r}\left(\frac{L}{\pi}\right)^{4}, H^{*}=\frac{H}{E I}\left(\frac{L}{\pi}\right)^{2}, V^{*}=\frac{V}{E I r}\left(\frac{L}{\pi}\right)^{3}, M^{*}=\frac{M}{E I r}\left(\frac{L}{\pi}\right)^{2}, \\
& w_{0}^{*}=\delta^{*} \sin \left(x^{*}\right)\left(0 \leq x^{*} \leq \pi\right), q^{*}=q_{0}^{*} \sin \left(x^{*}\right) \quad\left(0 \leq x^{*} \leq \pi\right)
\end{aligned}
$$


where $r$ is the radius of gyration of the cross section. Eqs.(5)-(7), (12)-(13) can be arranged in terms of the nondimensional parameters, as

$$
\begin{aligned}
& \bar{\varphi}^{*}=\frac{d \bar{w}^{*}}{d x^{*}}, \\
& q^{*}=\frac{d V^{*}}{d x^{*}}, \\
& \frac{d M^{*}}{d x^{*}}=V^{*}+H^{*}\left(\bar{\varphi}^{*}+\varphi_{0}^{*}\right), \\
& M^{*}=-\frac{d \bar{\varphi}^{*}}{d x^{*}}, \\
& H^{*}=\frac{1}{2 \pi} \int_{0}^{\pi}\left(\varphi_{0}^{* 2}-\varphi^{* 2}\right) d x^{*} .
\end{aligned}
$$

Using Eqs.(14), the nondimensional boundary conditions can be rewritten as

$$
\begin{aligned}
& \bar{w}^{*}(0)=\bar{w}^{*}(\pi)=0, \\
& M^{*}(0)=M^{*}(\pi)=0 .
\end{aligned}
$$

\section{Solution Method}

The ordinary differential equations given in Eqs.(16)-(19) are converted into nonlinear algebraic equations by means of the finite differences method. For this purpose, equally-spaced $n$ nodes along the span are used. Thus, the span of the initially imperfect beam is divided equally into (n-1) finite pieces, where the step size is given as $\Delta x^{*}$. There are four unknowns at each node $i$; namely $\bar{w}_{i}^{*}, \bar{\varphi}_{i}^{*}, V_{i}^{*}, M_{i}^{*}$. In addition, horizontal support reaction $H^{*}$ is not known. Thus, when $n$ points are considered, there are totally $(4 n-1)$ unknowns in the system.

In this study, the first-order forward difference formula with respect to $x^{*}$ is used for each node $i$ except for the last node:

$$
\left(\frac{d g}{d x^{*}}\right)_{i}=\frac{g_{i+1}-g_{i}}{\Delta x^{*}}+O\left(\Delta x^{*}\right) \quad i=1,2, \ldots .,(n-1)
$$

where $g$ is any unknown of the problem. $O$ denotes the order of the truncation error [15]. The truncation error can be noted to be decreased as the number of nodes is increased.

Using Eq.(21) for the derivatives in Eqs.(16)-(19), the corresponding set of nonlinear algebraic equations is, then, obtained as

$$
\begin{aligned}
& f_{1_{i}}=0=\Delta x^{*} \bar{\varphi}_{i}^{*}-\left(\bar{w}_{i+1}^{*}-\bar{w}_{i}^{*}\right), \\
& f_{2_{i}}=0=\Delta x^{*} q_{0}^{*} \sin \left(x_{i}^{*}\right)-\left(V_{i+1}^{*}-V_{i}^{*}\right), \\
& f_{3_{i}}=0=\Delta x^{*} H^{*}\left(\bar{\varphi}_{i}^{*}+\varphi_{0_{i}}^{*}\right)+\Delta x^{*} V_{i}^{*}-\left(M_{i+1}^{*}-M_{i}^{*}\right), \\
& f_{4_{i}}=0=\Delta x^{*} M_{i}^{*}+\left(\bar{\varphi}_{i+1}^{*}-\bar{\varphi}_{i}^{*}\right)
\end{aligned}
$$

for each $i$ where $i=1,2, \ldots \ldots,(n-1)$. Additionally,

$$
f_{5}=0=H^{*}+\frac{\Delta x}{2 \pi}\left[\frac{\left(\bar{\varphi}_{1}^{* 2}+2 \bar{\varphi}_{1}^{*} \varphi_{0_{1}}^{*}\right)}{2}+\left(\bar{\varphi}_{2}^{* 2}+2 \bar{\varphi}_{2}^{*} \varphi_{0_{2}}^{*}\right)+\left(\bar{\varphi}_{3}^{* 2}+2 \bar{\varphi}_{3}^{*} \varphi_{0_{3}}^{*}\right)+\ldots+\left(\bar{\varphi}_{(n-1)}^{*}+2 \bar{\varphi}_{(n-1)}^{*} \varphi_{0_{(n-1)}}^{*}\right)+\frac{\left(\bar{\varphi}_{(n)}^{*}+2 \bar{\varphi}_{(n)}^{*} \varphi_{0_{(n)}}^{*}\right)}{2}\right]
$$


can be written by using Eq.(20) and the trapezoidal rule. The nonlinear algebraic equations, Eqs.(2327), together with the boundary conditions (21) can be expressed in compact form as

$$
\text { A } \Delta \mathbf{y}=\mathbf{b}
$$

where $\mathbf{A}$ is the Jacobian matrix, $\Delta \mathbf{y}$ is the correction vector, and $\mathbf{b}$ is the right hand side vector. The matrix equation (28) can be solved numerically by using the Newton-Raphson method [16]. The number of equations can be checked to be equal to the number of unknowns.

Due to the convergence problem known to be occurring in the vicinity of the point where the slope of the force-deflection curve is zero [17-19], the rotation at the nth point, $\bar{\varphi}_{n}^{*}$, is chosen to be removed from the unknown (state) vector and used in the input data, instead of $q_{0}^{*} . q_{0}^{*}$ is put into the state vector as an unknown, in place of $\bar{\varphi}_{n}^{*}$. If the value of $\bar{\varphi}_{n}^{*}$ is taken to be zero, then the state vector will be equal to zero vector. If a small increment is given to $\bar{\varphi}_{n}^{*}$, then the zero vector for the correction vector becomes a reasonable initial estimate for the Newton-Raphson iterations. While obtaining solutions for the subsequent increments of $\bar{\varphi}_{n}^{*}$, the solution vector corresponding to the previous value of $\bar{\varphi}_{n}^{*}$ is used as the initial estimate. In this way, by using the Newton-Raphson method, convergence could be achieved for the solution vector corresponding to the various values of $\bar{\varphi}_{n}^{*}$. The computer program used in the numerical calculations is generated by the authors.

\section{Numerical Results and Interpretation}

In this section, the buckling and postbuckling behavior of the beam having initially small sinusoidal imperfection under sinusoidal loading is analyzed numerically. The value of the sinusoidal external load at the center of the arch $q_{0}^{*}$, the horizontal support reaction $H^{*}$, the deflections $\bar{w}_{i}^{*}$, effective shear forces $V_{i}^{*}$ and bending moments $M_{i}^{*}$ at each node $i$ of the initially imperfect beam corresponding to the selected values of the nondimensional initial imperfection parameter before the deformation $\delta^{*}$ are computed.

Comparing the values of the buckling loads determined by the computer program prepared in the present study for $\delta^{*}=3$ with those of Mortazavi et al. [20], who considered different sets of governing equations and boundary conditions (obtained via a variational analysis) and used the finite difference method and a control algorithm; 81 nodes are seen to be sufficient for correct results. The equilibrium paths of a sinusoidal initially imperfect beam with $\delta^{*}=3$ under the sinusoidal loading corresponding to the present study and Ref. [20], shown in Figure 3, are observed to be very close to each other. Mortazavi et al. [20] verified their very rigorous study by comparing their results with those of an analytical study [11].

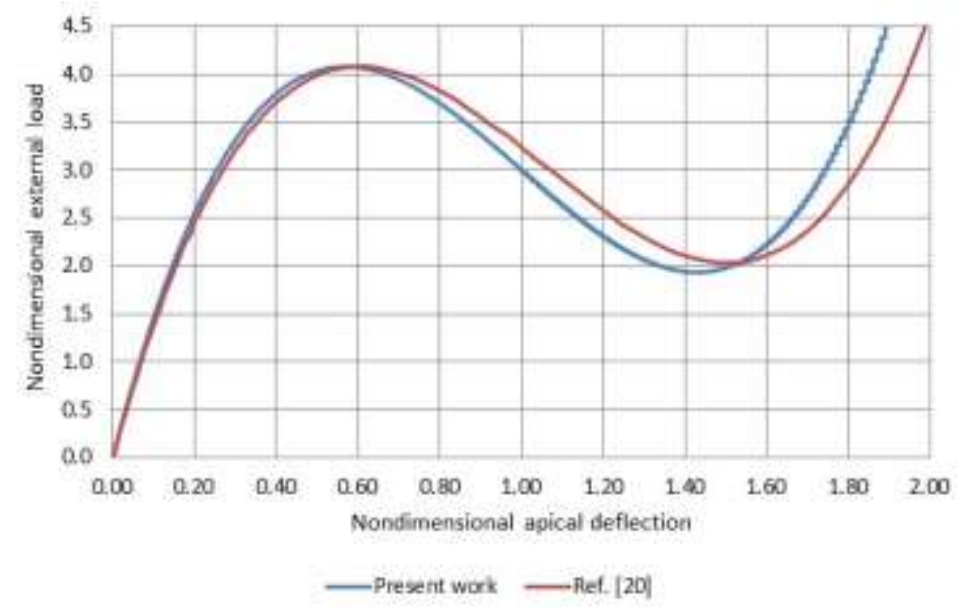

Figure 3. Comparison of the equilibrium paths 
Figure 4 shows the typical snap-through behaviors for the values of $\delta^{*}=3$ and $\delta^{*}=3.6$. The point $\mathrm{A}$ corresponds to the initial configuration. The peak point $\mathrm{C}$ corresponds to the buckling load, and the corresponding deflection is called the buckling deflection. As can be seen in the Figure $4 \mathrm{a}$ and $4 \mathrm{~b}$ by increasing the initial imperfection parameter, the buckling load is increased, but the buckling deflection is decreased. The equilibrium configurations between $\mathrm{A}$ and $\mathrm{C}$ are always stable. Once the load reaches the peak value at $\mathrm{C}$, the system suddenly jumps to the position $\mathrm{G}$ [21]. Although the equilibrium configurations between $\mathrm{C}$ and $\mathrm{E}$ are unstable, the equilibrium configurations between $\mathrm{E}$ and $\mathrm{G}$ indicate to the second stable equilibrium conditions. In the stable regions, the external force is increased as the midpoint deflection is increased and vice versa in the unstable region. As shown in Figure 4, in snap-through behavior, under the same load; the apical deflections of C and G (or B, D and F) are quite different from each other.

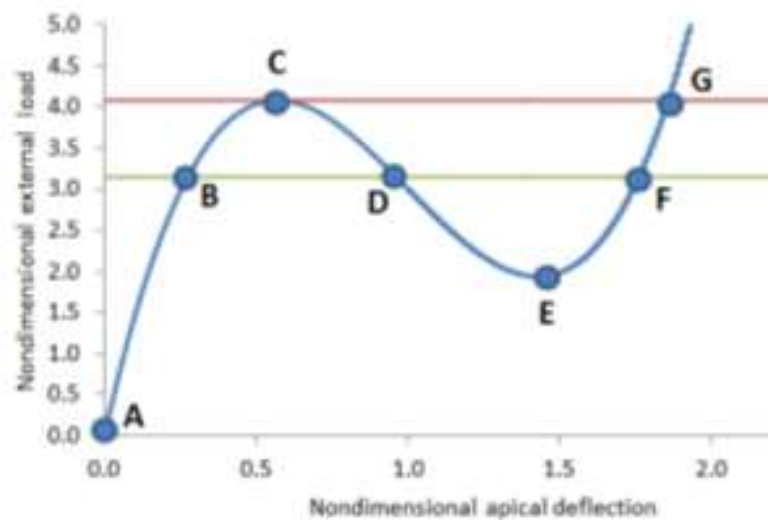

a)

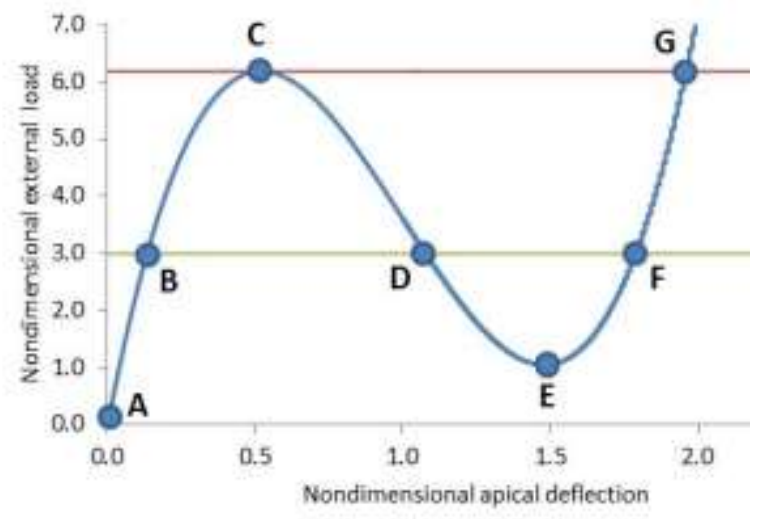

b)

Figure 4. The various stages of the equilibrium paths for a) $\delta^{*}=3$, b) $\delta^{*}=3.6$

Figure 5 demonstrates the nondimensional external load versus the nondimensional horizontal support reaction. The letters in Figure 5 relate to those shown in Figure 4. The horizontal support reaction is increased by increasing the external load up to the point $\mathrm{C}$, as indicated. However, after passing the point $\mathrm{E}$, the horizontal support reaction is decreased as the external force is increased. Figures $5 \mathrm{a}$ and $5 \mathrm{~b}$ show that as the initial imperfection parameter is increased, the support reaction corresponding to the buckling load is increased.

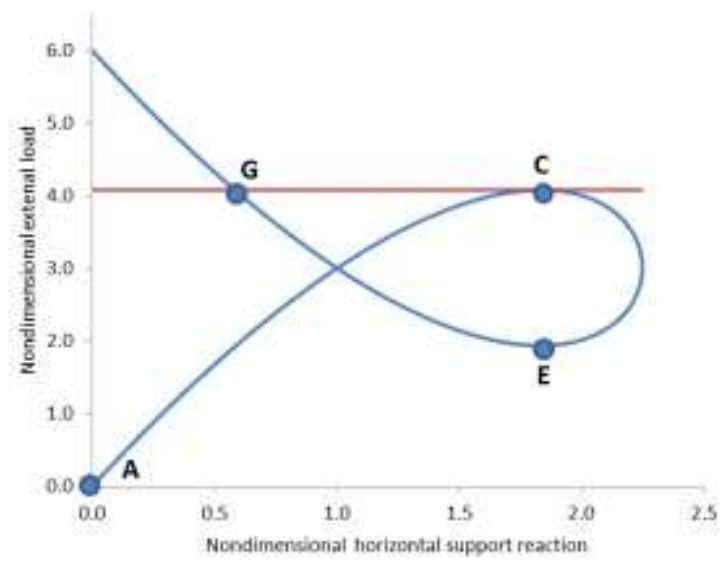

a)

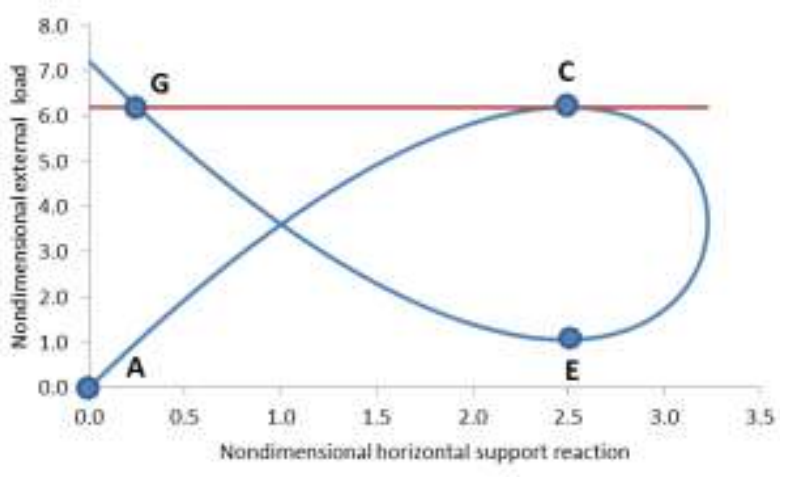

b)

Figure 5. External load versus horizontal support reaction diagrams for a) $\delta^{*}=3$, b) $\delta^{*}=3.6$

Figure 6 represents the undeformed and deformed configurations of the initially imperfect beam corresponding to the various stages of the deformation (shown in Figure 4) for $\delta^{*}=3$ and $\delta^{*}=3.6$. The elastic curve indicated by A belongs to the undeformed beam. The elastic curve B corresponds to the 
behavior in the first stable region between $\mathrm{A}$ and $\mathrm{C}$, given in Figure 4. The elastic curve $\mathrm{C}$ corresponds to the buckling. The elastic curve $\mathrm{D}$ presents the behavior in the unstable region between $\mathrm{C}$ and $\mathrm{E}$, shown in Figure 4. The elastic curve E corresponds to the deflection at the second limit point. The elastic curves corresponding to the point $\mathrm{F}$ and the point $\mathrm{G}$ show the behavior in the second stable equilibrium configurations, respectively.

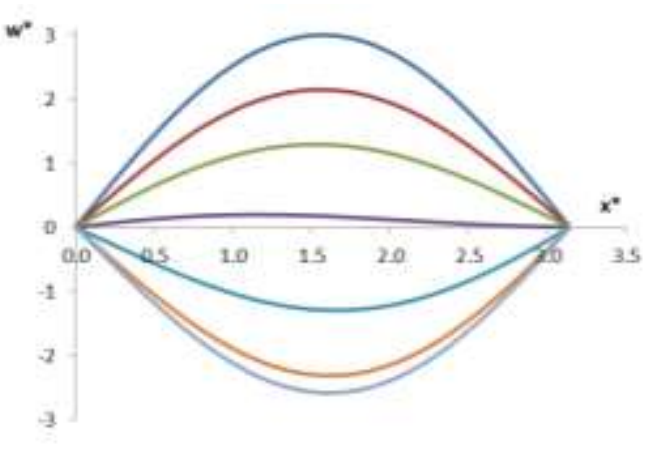

a)

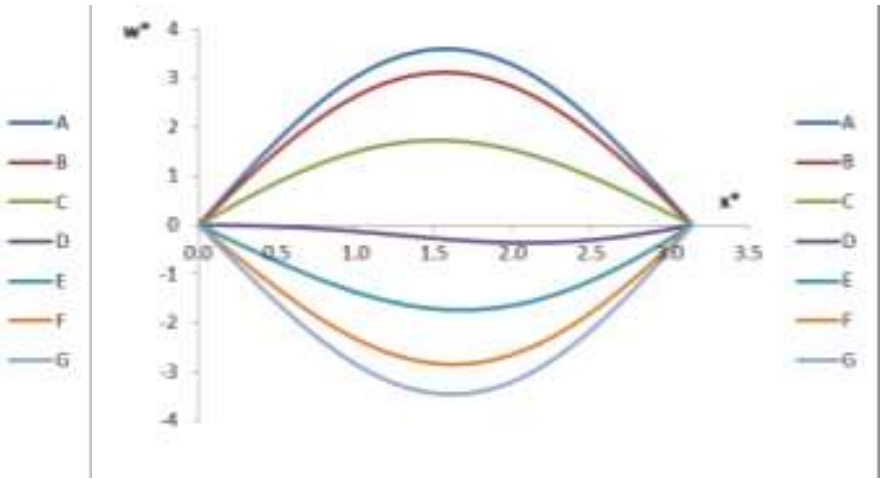

b)

Figure 6. Initial and deformed shapes at various stages of loading for a) $\delta^{*}=3$, b) $\delta^{*}=3.6$

Figure 7 demonstrates the bending moment diagrams corresponding to the various stages of the deformation, stated in Figure 4, for $\delta^{*}=3$ and $\delta^{*}=3.6$. In Figure 7, the absolute values of the bending moments are increased with the increase in the values of the apical deflections. The absolute values of the bending moment corresponding to the various stages of the deformation are increased as the initial imperfection parameter is increased.

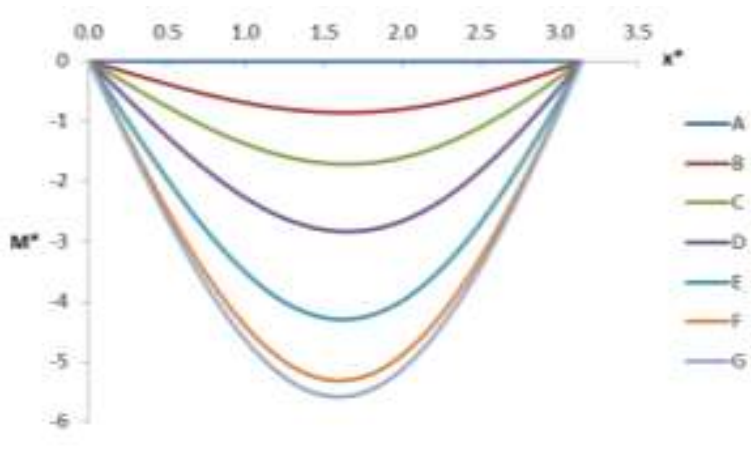

a)

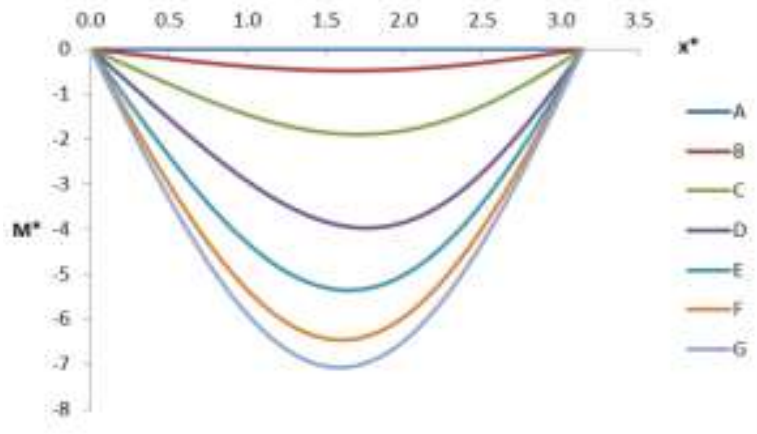

b)

Figure 7. The bending moment diagrams corresponding to the various stages of the deformation for a) $\delta^{*}=3$, b)

$$
\delta^{*}=3.6
$$

Figure 8 shows the effective shear force diagrams corresponding to the various stages of the deformation, stated in Figure 4, for $\delta^{*}=3$ and $\delta^{*}=3.6$. The effective shear force diagrams overlap on the C-G and B-D-F stages as the values of external load are same at these stages. Since the loading and support conditions are symmetrical, the diagrams pass through zero in the mid-span. The absolute values of the effective shear force corresponding to the various stages of the deformation are increased as the external force is increased. 


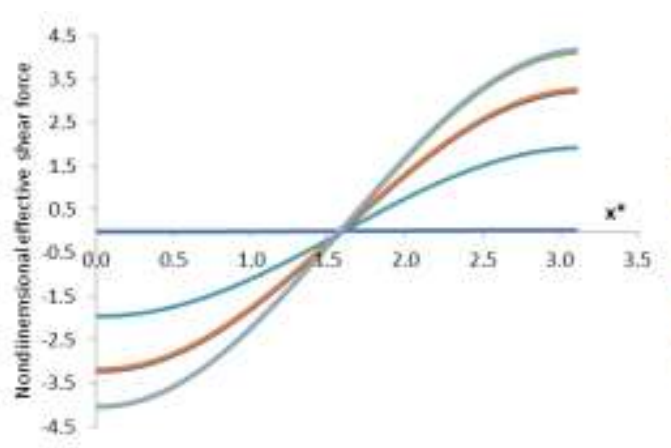

a)

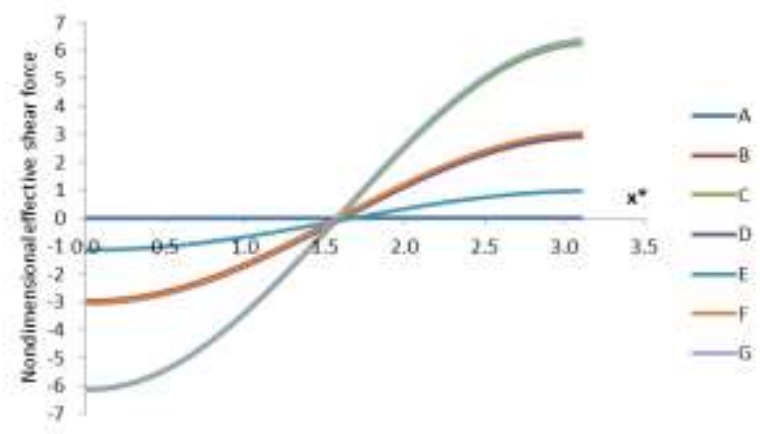

b)

Figure 8. Effective shear force diagrams for the various stages of the deformation for a) $\delta^{*}=3$, b) $\delta^{*}=3.6$

From the results in Figure 9; it is seen that when the value of the nondimensional initial imperfection parameter, $\delta^{*}$, is increased, for the same number of nodes, the corresponding buckling force is increased (Figure 9a), while the computed buckling midpoint deflection is decreased (Figure 9b).

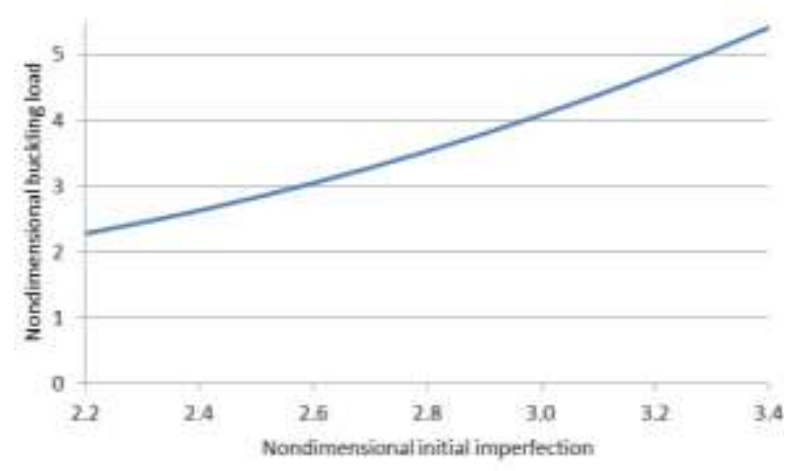

a)

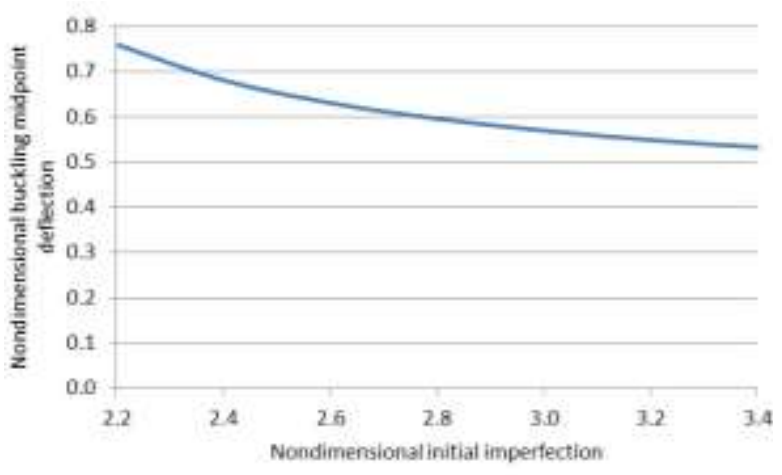

b)

Figure 9. Influence of the value of the nondimensional initial imperfection parameter on a) the buckling load, b) the buckling midpoint deflection

Figure 10 represents load-deflection curves for certain values of $\delta^{*}$. For the given values of $\delta^{*}$ in Figure 10; as the value of $\delta^{*}$ is increased, the snap-through buckling behavior becomes more pronounced.

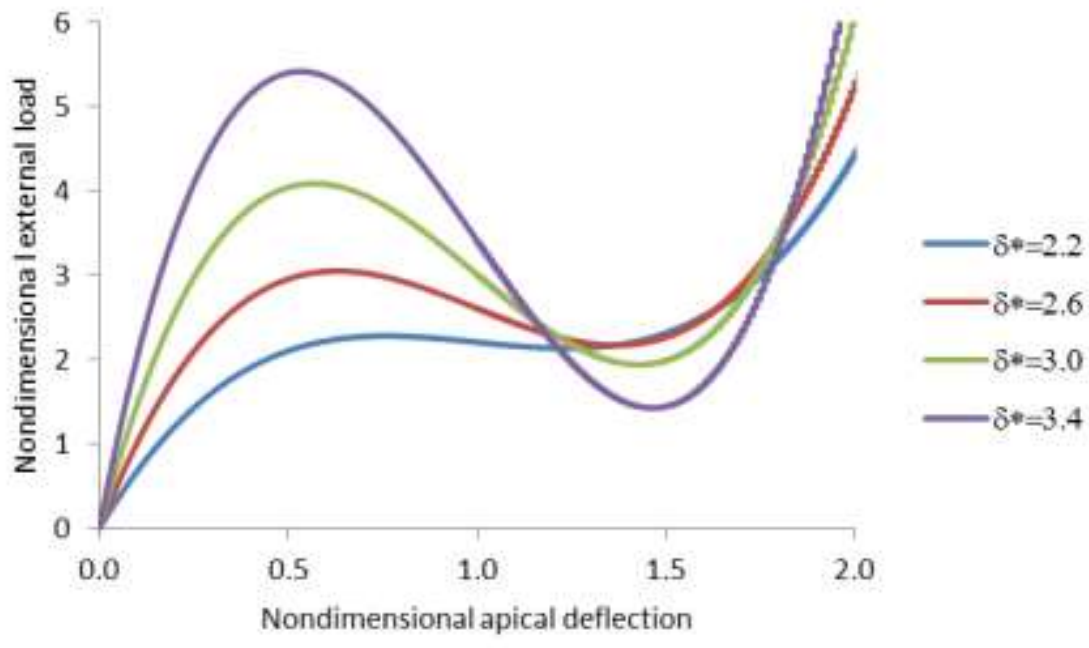

Figure 10. Load-deflection curves for certain values of initial imperfection 
Figure 11 demonstrates the nondimensional horizontal support reaction versus nondimensional external load for various values of the initial imperfection. It is seen that the distance between the points (in the $\mathrm{q}^{*}-\mathrm{H}^{*}$ diagram) corresponding to the first and second limit points ( $\mathrm{C}$ and $\mathrm{E}$ points in Figure 4, respectively) is increased as the value of $\delta^{*}$ is increased.

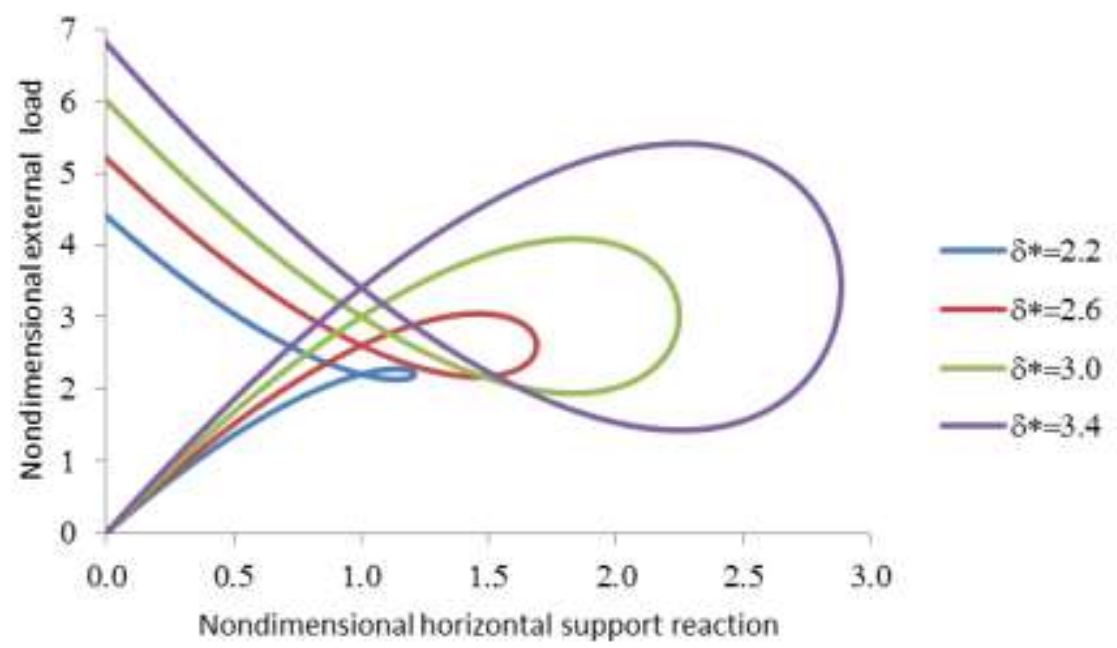

Figure 11. The nondimensional horizontal support reaction versus the nondimensional external load for various initial imperfection values

\section{Concluding Remarks}

In the present paper, the snap-through behavior of the pinned beams having initially sinusoidal imperfection subjected to the sinusoidal load is examined. The corresponding geometrically nonlinear problem is solved numerically by using the finite difference and Newton-Raphson methods. The values of the buckling load and buckling deflection are determined by using the equilibrium paths for various values of the initial imperfection. The diagrams of the deformed shapes of the beam having initially small imperfection and the diagrams of the internal forces are presented for the prebuckling, buckling and postbuckling states.

According to the results obtained, as the value of the initial imperfection parameter is increased, the corresponding buckling force is increased (Figure 9a) and the snap-through buckling behavior becomes more pronounced (Figure 10). On the other hand, the computed buckling midpoint deflection is decreased as the initial imperfection is increased (Figure 9b).

It can be observed from the nondimensional external load versus the nondimensional horizontal support reaction diagram (see Figure 5) that the slopes of the corresponding curve are zero for the first and second limit points where the slopes of the force-deflection diagram (see Figure 4) are zero. The horizontal support reaction is increased by increasing the external load up to the first peak point $(\mathrm{C})$ in the equilibrium path diagram. After passing the limit point $\mathrm{E}$, second stable equilibrium configuration, the horizontal support reaction continues to decrease, despite the rise observed in the external load (Figure 5). Moreover; the distance between the points (in the $\mathrm{q}^{*}-\mathrm{H}^{*}$ diagram) corresponding to the first and second limit points ( $\mathrm{C}$ and $\mathrm{E}$ points in Figure 5, respectively) is increased as the value of $\delta^{*}$ is increased (Figure 11).

The sign of the curvature of the deformed beam is changed at a stage of the deformation between the first limit point and the second limit point (Figure 6).

The diagrams of the bending moments at various stages of the deformation are symmetrical as the support and loading conditions are symmetrical. The absolute values of the bending moments are increased during the snap-through process (Figure 7).

The effective shear force diagrams are seen as parabolic in various stages of the deformation. The effective shear force diagrams overlap when the values of external load are the same at some stages. 
At the point where moment diagrams pass from maximum, shear force diagrams pass from zero (Figure 8). The absolute value of the effective shear force is increased as the values of the external force or the initial imperfection is increased.

Diagrams of elastic curves and internal forces for the different values of $\delta^{*}$ are drawn, and it is seen that with the change of $\delta^{*}$, the corresponding values are changed, but the interpretations remain similar.

It should be noted that the variation of the value of the span of the beam, $L$, and the radius of gyration of the cross section, $r$ (dimensional parameters), do not alter the dimensionless physical quantities due to their being excluded in the dimensionless boundary value problem (Eqs. (16-21)).

In the present study, the buckling and postbuckling behaviors of beams having small sinusoidal imperfection with pinned ends subjected to sinusoidal loading are investigated. Other types of support and loading conditions are not within the scope of this study. However, those interested in the effect of the concerning parameters on the buckling behavior can refer to [22] for the fixed support type and [20] for the uniform loading.

\section{Authors' Contribution}

Ayfer TEKIN ATACAN Conceptualization, Methodology, Software, Writing - Review \& Editing, Project administration, Formal analysis, Validation, Investigation, Resources, Data Curation, Visualization, Writing original draft. Receb Faruk YÜKSELER Conceptualization, Methodology, Software, Writing - Review \& Editing, Project administration, Formal analysis, Supervision.

\section{Statement of Conflicts of Interest}

The authors have no competing interests to declare.

\section{Statement of Research and Publication Ethics}

The authors complied with research and publication ethics.

\section{References}

[1] Das K., Batra R.C. 2009. Symmetry Breaking, Snap-Through and Pull-In Instabilities under Dynamic Loading of Microelectromechanical Shallow Arches. Smart Materials and Structures, 18 (11): Article Number: 115008.

[2] Gerson Y., Krylov S., Ilic B. 2010. Electrothermal Bistability Tuning in a Large Displacement Micro Actuator. J. Micromech. Microeng., 20 (11): Article Number: 112001.

[3] Medina L., Gilat R., Ilic B., Krylov S. 2014. Experimental Investigation of the Snap-Through Buckling of Electrostatically Actuated Initially Curved Pre-Stressed Micro Beams. Sensors and Actuators A: Physical, 220 (1): 323-332.

[4] Beharic J., Lucas T.M., Harnett C.K. 2014. Analysis of a Compressed Bistable Buckled Beam on a Flexible Support. Journal of Applied Mechanics-Transactions of the ASME, 81 (8): Article Number: 081011.

[5] Chen X., Meguid S.A. 2015. Snap-Through Buckling of Initially Curved Microbeam Subject to an Electrostatic Force. Proceedings of the Royal Society A, 471 (2177):Article Number: 20150072.

[6] Bradford M.A., Uy B., Pi Y.L. 2002. In-plane Elastic Stability of Arches under a Central Concentrated Load. Journal of Engineering Mechanics-ASCE, 128 (7): 710-719.

[7] Chen J.S., Ro W.C., Lin J.S. 2009. Exact Static and Dynamic Critical Loads of a Sinusoidal Arch under a Point Force at the Midpoint. Int. J. Nonlin. Mech., 44 (1): 66-70.

[8] Moon J., Yoon K.Y., Lee T.H., Lee H.E. 2007. In-plane Elastic Buckling of Pin-Ended Shallow Parabolic Arches. Eng. Struct., 29 (10): 2611-2617.

[9] Hu C.-F., Pi Y.-L., Li W.G. 2018. In-Plane Non-Linear Elastic Stability of Parabolic Arches with Different Rise-to Span Ratios. Thin-Walled Structures, 129: 74-84. 
[10] Fung Y.C., Kaplan A. 1952. Buckling of Low Arches or Curved Beams of Small Curvature. NACA Technical Note, No: 2840.

[11] Simitses G.J., Hodges D.H. 2006. Fundamentals of Structural Stability. Elsevier, Burlington, MA.

[12] Luu A.T., Lee J. 2016. Non-Linear Buckling of Elliptical Curved Beams, International Journal of Non Linear Mechanics, 82: 132-143.

[13] Liu N., Plucinsky P., Jeffers A.E. 2017. Combining Load-Controlled and DisplacementControlled Algorithms to Model Thermal-Mechanical Snap-Through Instabilities in Structures. J. Eng. Mech., 143 (8): Article Number: 04017051.

[14] Tsiatas G.C., Babouskos N.G. 2017. Linear and Geometrically Nonlinear Analysis of NonUniform Shallow Arches under a Central Concentrated Force. Int. J. Non-Linear Mech., 92: 92101.

[15] Mathews J.H. 1992. Numerical Methods for Mathematics, Science and Engineering. PrenticeHall International Inc., USA.

[16] Maron M.J., Lopez R.J. 1991. Numerical Analysis: A Practical Approach. Wadsworth Publishing Company, Belmont.

[17] Altekin M., Yükseler R.F. 2008. A Parametric Study on Geometrically Nonlinear Analysis of Initially Imperfect Shallow Spherical Shells. Journal of Elastomers and Plastics, 40 (1): 253-270.

[18] Yıldırım B., Yükseler R.F. 2011. Effect of Compressibility on Nonlinear Buckling of Simply Supported Polyurethane Spherical Shells Subjected to an Apical Load. Journal of Elastomers and Plastics, 43 (2): 167-187.

[19] Yıldırım B., Yükseler R.F. 2014. Combined Effect of Compressibility, Height and Thickness on the Nonlinear Behaviour of Polyurethane, Simply-Supported Spherical Shells under Apical Loads. Bitlis Eren Univ J Sci \& Technol., 4 (1): 12-19.

[20] Mortazavi P., Mirdamadi H.R., Shahidi A.R. 2018. Postbuckling, Limit Point, and Bifurcation Analyses of Shallow Nano-Arches by Generalized Displacement Control and Finite Difference Considering Small-Scale Effects. International Journal of Structural Stability and Dynamics, 18 (1): Article Number: 1850014.

[21] Pflüger A. 1964. Stabilitats Probleme der Elastostatic. Springer Verlag, Berlin.

[22] Dimopoulos C.A., Gantes C.J. 2008. Nonlinear In-Plane Behavior of Circular Steel Arches with Hollow Circular Cross-Section. Journal of Constructional Steel Research, 64 (12): 1436-1445. 